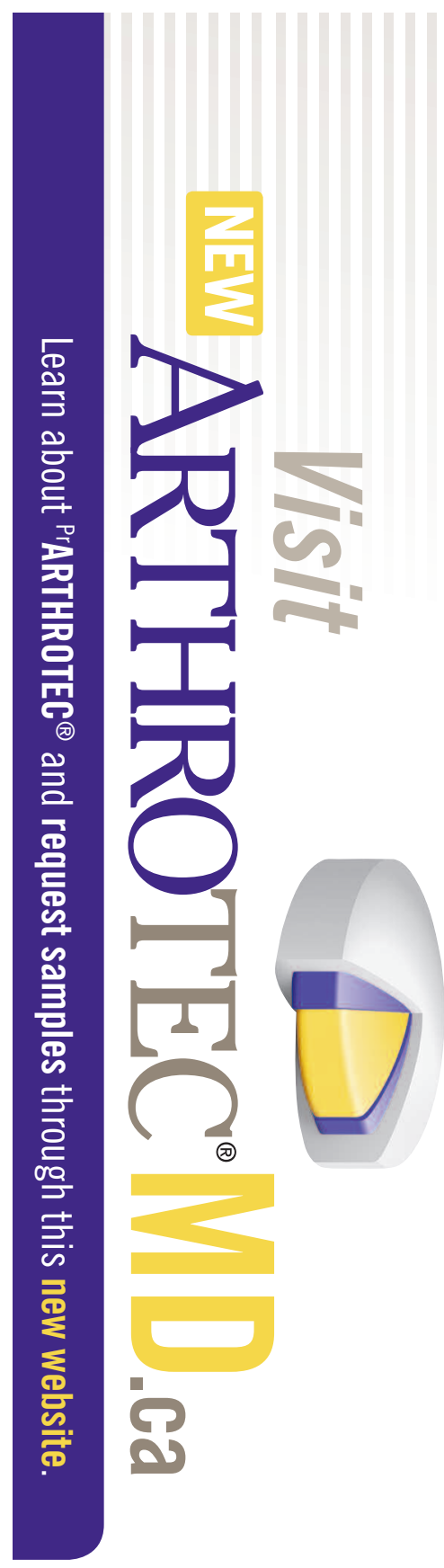

An NSAID with a mucosal protective agent, ${ }^{\text {PrARTHROTEC }}{ }^{\circledR}$ (50 \& 75 mg diclofenac sodium and misoprostol tablets) has contraindications as well as warnings and precautions of use.

Please consult the Prescribing Information which is available on the ARTHROTECMD.ca website, or the Product Monograph which is available upon request.

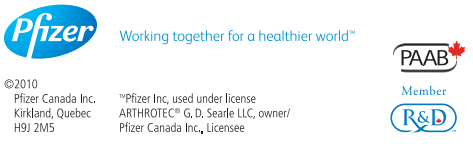

LETTERS

\section{And that's not all ...}

I wholeheartedly concur with Chorley, McGrath and Finlay, and their observations and conclusions about the pain associated with treatment that we inflict on our patients. ${ }^{1}$ I would add a similar consequence of our treatment: habituation and addiction to the narcotics we inflict on some patients whose pain we try to alleviate. Often the pain that we first believe is acute transpires to be chronic. Once the dose of a drug has been titrated in pursuit of a level of relief that seems to become ever more elusive, the patient develops numerous adverse symptoms, including hyperesthesia, constipation, hyperhydrosis and endocrine disorders, such as testosterone suppression. Habituation often leads to addiction. But when we awaken to the situation, we are confronted with the prospect of having to induce most uncomfortable withdrawal symptoms. Who then can blame us for occasionally turning a blind eye to patients in pain rather than risk such an outcome?

\section{Antony Hammer MB BS}

Erie-St Clair Clinic, Windsor, Ont.

\section{REFERENCE}

1. MacLaren Chorney J, McGrath P, Finley GA. Pain as the neglected adverse event. CMAJ 2010;182: 732

For the full letter, go to: www.cmaj.ca/cgi/eletters /182/7/732\#360829

DOI:10.1503/cmaj.110-2078

\section{Mandatory ski helmets?}

In their meta-analysis on the effects of helmets on the risk of head and neck injuries among skiers and snowboarders, ${ }^{1}$ Russell and colleagues found a $35 \%$ reduced risk of head injury when a ski helmet was used. Recently, we showed a similar reduction in the number of head injuries in skiers and snowboarders involved in falls and collisions in the winter season $2008-09 .{ }^{2} \mathrm{We}$ strongly assume that the beneficial effects of helmet use are even underestimated when using controls with injuries below the head. This assumption is based on the fact that higher rates of helmet use have been observed in uninjured compared with injured skiers and snowboarders. In the 2009 10 winter season, helmets were mandatory for children under the age of 15 years in most Austrian provinces. Future investigations are needed to evaluate the impact of mandatory rules on increasing helmet use and reduced risk of head injury, especially in children.

\section{Gerhard Ruedl PhD \\ Martin Kopp PhD \\ Martin Burtscher MD PhD \\ Department of Sport Science, Innsbruck, Austria}

\section{REFERENCES}

1. Russell K, Christie J, Hagel BE. The effect of helmets on the risk of head and neck injuries among skiers and snowboarders: a meta-analysis. CMAJ 2010;182:333-40.

2. Ruedl G, Sommersacher R, Woldrich T, et al. Risk factors of head injuries on Austrian ski slopes. Dtsch Z Sportmed 2010;61:16-21.

For the full letter, go to: www.cmaj.ca/cgi/eletters /182/4/333\#333045

DOI:10.1503/cmaj.110-2072

\section{Correction}

The article "Hippocrates in Quebec: The films of Bernard Émond," published Apr. 20, 2010, stated that the first film in Émond's trilogy was $L a$ Veuvaine (The Novena). In fact, it is titled La Neuvaine. CMAJ regrets any inconvenience this error may have caused.

\section{REFERENCE}

1. McSorley T. Hippocrates in Quebec: The films of Bernard Émond. CMAJ 2010;182:701-2.

DOI: $10.1503 / \mathrm{cmaj} .110-2081$

\section{Letters to the editor}

In submitting a letter, you automatically consent to have it appear online and/or in print. All letters accepted for print will be edited by $C M A J$ for space and style. Most references and multiple authors' names and full affiliations will appear online only. (The full version of any letter accepted for print will be posted at cmaj.ca.) 